\title{
Water temperature influences larval survival of the amphidromous goby Sicyopterus lagocephalus
}

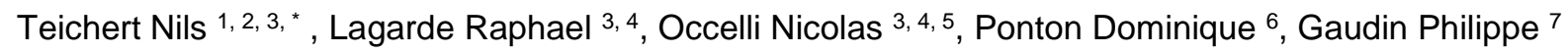

${ }^{1}$ Laboratoire de Biologie des Organismes et Ecosystèmes Aquatiques (BOREA) MNHN CNRS IRD SU

UCN UA Paris ,France

${ }^{2}$ MNHN Station Marine de Dinard Dinard, France

${ }^{3}$ Hydrô Réunion, Z.I. Les Sables La Réunion, France

${ }^{4}$ Centre de Formation et de Recherche sur les Environnements Méditerranéens Université de

Perpignan Via Domitia - CNRS Perpignan ,France

${ }^{5}$ Master: Gestion de l'Environnement valorisation des ressources naturelles Università di Corsica

Pasquale Paoli Corte, France

${ }^{6}$ ENTROPIE IRD Université de La Réunion CNRS Université de la Nouvelle-Calédonie Ifremer c/o Institut Halieutique et des Sciences Marines (IH.SM) Université de Toliara Toliara, Madagascar

7 Université de Pau et des Pays de l'Adour e2s UPPA INRAE ECOBIOP Aquapôle INRAE Saint-Péesur-Nivelle ,France

*Corresponding author : Nils Teichert, email address : nils.teichert@mnhn.fr

\begin{abstract}
:
Water warming induced by human activities can impact fish larvae survival, notably because it influences larval development and prey abundances. Amphidromous gobies of the subfamily Sicydiinae are particularly sensitive to this threat as the newly hatched free embryos are poorly developed and the first feeding opportunity only occurs after they reach the ocean. Here, we studied how water temperature (21, $23,25,29$ and $31^{\circ} \mathrm{C}$ ) impacts early development stages of Sicyopterus lagocephalus in both freshwater and marine aquaria (salinity 35). We monitored survival time, larval condition and the occurrence of critical developmental events such as mouth opening, yolk sac and oil globule resorption. In freshwater, the survival exceeded 150 hours at $21^{\circ} \mathrm{C}$, while it dropped below 50 hours at $31^{\circ} \mathrm{C}$. In seawater, the larval development of unfed larvae was significantly affected by temperature, survival time being greatly reduced in warmer waters. Accounting for the observed duration between mouth opening and the resorption of the oil globule, we estimated that larvae need to find suitable prey in seawater within a short time: around 30 hours during the peak of reproduction in summer. Otherwise, their endogenous reserves become depleted and their condition degrades. This study emphasises the sensitivity of free embryos to stream flow alterations, which contributes to the increase in water temperature and to the slowing down of larvae drift to the ocean. We conclude that once in seawater the temperature and feeding conditions experienced by amphidromous larvae are critical for survival.
\end{abstract}

Keywords : amphidromy, early life history, larval survival, mixed feeding period, starvation, water warming 


\section{Introduction}

Mortality during fish early life is huge and highly variable, inducing important fluctuations in the abundance of adults (Hjort, 1914; Houde \& Schekter, 1980). Among the hypotheses proposed to explain fish larvae mortality, starvation remains a major cause (China \& Holzman, 2014). More specifically, important mortality rates have been associated with the first feeding period when the individuals must switch from endogenous to exogenous feeding (Hjort, 1914). This narrow period, usually referred as a "critical period" for larvae, coincides with the complete yolk resorption and the onset of active foraging. Newly hatched individuals have to find and capture food to survive before their endogenous reserves become fully depleted, otherwise they can reach an irreversible starvation state (Fyhn, 1989; Iguchi \& Mizuno, 1999; Gisbert, Conklin \& Piedrahita, 2004). However, the moment when this critical period occurs varies among species depending on their initial endogenous reserves and their development stage at hatching (McCasker et al., 2014). While some species hatch with a functional mouth and the alimentary tract well developed, others remain so poorly developed at hatching that some authors identify them as free embryos (Balon, 1975). For these species, the initiation of external feeding is delayed (Kamler, 2012). Their first food intake usually occurs during the short period of time between the opening of the mouth or esophagus (Bardonnet et al., 1993) and the complete depletion of endogenous reserves. For these species, suitable prey must be rapidly ingested or first physiological signs of food deprivation occur (Gisbert, Conklin \& Piedrahita, 2004; McCasker et al., 2014).

The amphidromous gobies can be observed in numerous coastal streams and rivers of tropical islands (Keith, 2003). The adults grow and reproduce in rivers. Immediately after hatching, the free embryos drift to the sea where the larvae develop for months before returning in rivers (Bell, 1994; McDowall, 2009). This transition between the fresh- and marine waters at an early developmental stage enhances the sensitivity of these species to environmental disturbances (McRae, 2007; Walter et al., 2012; Jarvis \& Closs, 2019). For example, rivers flow reduction due to water abstraction, or presence of reservoirs along the river courses, will expand the time required for individuals to reach the sea, while the water in which they drift warms up (Brasher, 2003; Jarvis \& Closs, 2019). In oceanic waters, the temperature records over the recent decades indicate a warming $>0.1{ }^{\circ} \mathrm{C}$ per decade in the western tropical Indian Ocean (Roxy et al., 2014). Warmer oceanic waters may induce changes in larval stage duration and increase larval mortality (Walter et al., 2012; Teichert, Valade, Grondin, et al., 2016). Indeed, growth, and thus yolk depletion, are accelerated at higher temperature (Dou et al., 2005; Yoseda et al., 2006). Such a statement is worrying in the context of global change as temperature of fresh-and marine waters are expected to increase while rivers may become more fragmented and/or regulated (Woodward, Perkins, \& Brown, 2010; McLeod et al., 2013; Watson et al., 2018). As a consequence, the abundances 
of larvae returning to estuaries, and thus those of adults in reproductive habitats, may sharply decrease in the future (Iguchi \& Mizuno, 1999; Jarvis \& Closs, 2015; Lagarde et al., 2018).

Only few studies have described the effects of altered temperature regimes on the embryos and larvae survival of amphidromous fish, particularly in regard to the critical period (Valade et al., 2009; lida et al., 2010, 2017). For species from the Sicydiinae subfamily, the mortality of the larvae during the critical period is expected to be elevated (Artzrouni, Teichert, \& Mara, 2014). This high mortality is likely due to their small size and their poor development when they hatch (McCasker et al., 2014). Females of Sicydiinae gobies usually spawn several thousands of $\leq 0.5 \mathrm{~mm}$ eggs on multiple occasions during an extended reproductive season (Manacop, 1953; Ha \& Kinzie, 1996; lida, Watanabe, \& Tsukamoto, 2013; Teichert, Valade, Fostier, et al., 2016). During their downstream drift to the sea, free embryos benefit from their endogenous reserves to survive while their eyes, mouth and digestive tract remain not functional (lida et al., 2010). Indeed, the newly hatched free embryos do not develop until they are exposed to brackish or marine water (Valade et al., 2009; lida et al., 2010; Ellien et al., 2011, 2020) where they acquire the morphological attributes of marine pelagic larvae (Bell \& Brown, 1995; Ellien, Werner, \& Keith, 2016). After the opening of their functional mouth, the larvae start feeding on exogenous prey while still benefiting from some remaining endogenous reserves. If larvae do not ingest food during this mixed feeding period, their physiological state deteriorates rapidly as they must draw energy from their muscles and tissue reserves (Moriyama et al., 1998; Iguchi \& Mizuno, 1999). Consequently, an important depletion of initial reserves before the mouth opens will shorten the period of time when larvae must find exogenous food, and thus decrease their survival. Survival may also be influenced by higher water temperature as it increases the development rate and thus hastens the exhaustion of endogenous reserves (Valade et al., 2009; lida et al., 2010; Ellien, Werner, \& Keith, 2016).

This study aimed at investigating the influence of temperature on larval survival and early life events of the amphidromous goby Sicyopterus lagocephalus. We hypothesized that warmer waters will increase the larval mortality and reduce the temporal window for the first food intake because of the first signs of starvation should occur earlier. Accordingly, the occurrence of critical larval life events such as the mouth opening, yolk sac resorption, and oil globule resorption, as well as larval condition, were monitored at different water temperatures. These elements helped assessing the impact of river alterations and oceanic warming on this widespread species during early life stage, and providing general insights on the ecology of amphidromous species.

\section{Materials and methods}

\subsection{Studied species and egg clutch collection}


Sicyopterus lagocephalus is a widespread amphidromous goby, distributed from Western Indian ocean to Eastern Pacific (Lord et al., 2012). On Reunion Island, in the West Indian Ocean, it dominates the freshwater fish assemblages from the river mouth to more than $30 \mathrm{~km}$ upstream (Lagarde et al., 2020). While this species can reproduce throughout the year in the downstream river reaches, the spawning season is restricted to the warmer months in the middle and upper sections of streams (Teichert et al., 2014). Accordingly, a marked drift peak of free embryos is observed during the Austral summer (Lagarde et al., 2017), when water temperatures in rivers and coastal areas are maximal.

Between March and May 2014, six egg clutches of S. lagocephalus were collected in the Langevin River, southwest of the Reunion Island, $2.8 \mathrm{~km}$ from the river mouth. A restricted number of clutches was collected to limit the impact on wild population. Egg clutches of this species are laid as clusters stuck on the underside of river stones (Delacroix \& Champeau, 1992). They can be found by turning over the stones (Teichert et al., 2013). While the newly laid eggs are white, their color progressively turns gray as embryos develop. Free embryos ( $1.7 \mathrm{~mm}$ TL; Ellien et al., 2016) are ready to hatch about $48 \mathrm{~h}$ post fertilization (Ellien et al., 2011). In this study, we collected newly laid egg clutches to avoid a precipitate hatching that may have affected free embryos survival, and to ensure that all eggs experienced similar laboratory conditions during the incubation phase. The eggs were carefully removed from their stones and transferred in a cooler to limit the thermal changes during the transport to the laboratory.

\subsection{Experimental design and conditions}

In the laboratory, each egg clutch was placed in a beaker filled with $500 \mathrm{ml}$ river water, and positioned in a water bath where the temperature was kept at $23.0^{\circ} \mathrm{C}$ using aquarium heaters $(\mathrm{Ht}-2100$, thermostat TS 500). Egg clutches were monitored every two hours to identify the hatching period that is usually restricted to a few hours. The eggs hatched between 22 and 42 hours after collection in the river. Once hatching began, the remaining eggs were placed in another beaker for one hour to collect all the free embryos hatching within this restricted period of time. Then, following an initial two hours in $23.0^{\circ} \mathrm{C}$ freshwater, the newly hatched free embryos were placed into their respective freshwater or marine treatment conditions. This delay was chosen to simulate the drifting duration of free embryos hatching about two kilometers upstream of the river mouth (Lagarde et al., 2018).

During the experiments, the lighting conditions were 12L: 12D using artificial lights. Larvae were not fed to determine how thermal regimes influence the time taken to reach irreversible starvation. Six thermal conditions were tested in freshwater $\left(21,23,25,27,29\right.$ and $\left.31^{\circ} \mathrm{C}\right)$ to cover the thermal range that free embryos can experience in Reunionese rivers. The lowest value corresponds to the temperature at which all S. lagocephalus females initiate their oocyte maturation (Teichert et al., 2014), while $31^{\circ} \mathrm{C}$ corresponds the highest temperature recorded in lower river reaches. For seawater experiments, the 
salinity was set to 35 using special Instant Ocean salt (Aquarium Systems) diluted in river water. Five thermal conditions were tested in seawater $\left(23,25,27,29\right.$ and $\left.31^{\circ} \mathrm{C}\right)$ to reflect the range of water temperatures recorded in coastal areas of Reunion Island (Conand et al., 2008; OCEA Consult', SaintPierre, Reunion Isl., unpublished data).

The water temperature was recorded every three minutes using automatic recorders (Tinytag TG 4100). In the following analyses, the temperatures recorded during the experimental surveys were used instead of the planned ones because some derivation was noted due slight imprecision in thermostats of aquarium heaters (Table 1). Despite these moderate shifts, the temperature variations (i.e. standard deviations) remained very low across experiments, such that records provided adequate estimates of thermal conditions experienced by larvae.

\subsection{Assessment of larval survival}

As the number of egg clutches collected in the wild was limited, free embryos of a same clutch were placed in two different experimental conditions except for eggs of clutch \#5 (Table 1). Another consequence of the low number of clutches was that all the individuals of each experimental condition originated from the same egg clutch. For each condition, five experimental $45 \mathrm{~mm}$ deep beakers were filled with $250 \mathrm{ml}$ of fresh- or seawater. In four beakers, each 40 free embryos were carefully transferred using a $5 \mathrm{ml}$ sampling pipette to assess their survival over time. Three of these beakers were used as replicates for the chosen experimental condition while the fourth corresponded to identical controlled conditions: $23.9^{\circ} \mathrm{C} \pm 0.1$ in freshwater (Fig. 1). Finally, about 250-300 larvae were transferred in the fifth beaker to record the development and condition of individuals placed in the chosen experimental condition (Fig. 1). The temperature of the four beakers was progressively shifted from the initial $23^{\circ} \mathrm{C}$ to the target experimental conditions by modifying the thermostat of water baths' heaters. The thermal change usually required between two and three hours before the temperature stabilized. The mortality was monitored every three hours during the day and every 3-4 hours during the night. An individual was considered dead when it had stopped its "swim up-sink down" behavior (Bell \& Brown, 1995; Valade et al., 2009) and lied immobile on the bottom of the beaker. Death was confirmed when it did not respond to stimulation with a paintbrush (Lagarde et al., 2018). All dead individuals were counted and removed from the beaker using a $15 \mu \mathrm{l}$ micropipette.

The influence of temperature on survival was analyzed separately for freshwater and seawater conditions using mixed survival regression models, assuming a Weibull distribution of the response variable (exponential, log-Gaussian and log-normal distributions were tested, but rejected). The survival was modeled according to the temperatures expressed as a continuous log-transformed variable as this transformation significantly improved the adjustment of survival models. The three replicates were 
173 included as random effects in the models to account for the non-independence among them. Finally, 174 an analysis of variance (ANOVA) for survival data was conducted to assess the significance of 175 temperature on larval survival. The generalized R2 statistic extended to survival models was used to 176 assess the adjustment of models (Li \& Wang, 2019).

177 The survival times of individuals placed in the control beaker were compared between egg clutches 178 based on the Kaplan-Meier method and tested using a log-rank test. This analysis aimed at assessing 179 the robustness of our findings despite the fact that free embryos originated from a unique clutch within 180 each thermal conditions. This analysis thus allowed for controlling for possible genetic effects, e.g. 181 maternal effect.

\subsection{Observation of larval development}

The larval development and body condition were only monitored in seawater as ontogenetic processes stopped in freshwater (Valade et al., 2009; Ellien et al., 2011). As long as a brackish stimulus did not occur, yolk sack resorption, mouth opening or oil globule resorption did not take place (Ellien et al., 2011, 2020).

At each monitoring session in seawater conditions, three to five individuals were collected from the fifth beaker, euthanized with an overdose of clove oil, and fixed in $4 \%$ formaldehyde. The number of individuals varied between monitoring session because of mortality increased over the time. Each individual was observed under light microscopy to detect if yolk sac resorption, mouth opening, or oil globule resorption had occurred (Fig. 2a). While the resorption of the yolk sac and oil globule give insights on the depletion of endogenous reserves, the opening of a functional mouth indicates when a larva becomes able to consume exogenous food. Additionally, a larval condition index (LCI) was calculated to estimate the collapse of skeletal muscle fibers due to starvation. This index was defined by the ratio between the body depth (BD) measured behind anus and the total length (TL). Lower $L C l$ values were expected when individuals become atrophied because of muscles' alteration. The measurements were conducted using image processing (Image J software) on pictures took with a camera (Olympus C-5060) under light microscopy (Olympus CX41).

The influence of water temperature on yolk sac resorption, mouth opening, and oil globule resorption, was analyzed over the time using logistic Generalized Linear Models (GLMs). Each characteristic was coded as 1 when observed or 0 when not present. The occurrence probabilities of each characteristic were modeled using the time after hatching (i.e. the age of the individuals) and the temperature as continuous explanatory variables, while considering the interaction terms. In this analysis, the temperature values were also log-transformed to improve the adjustment of models. Deviance 
reduction tests (ANOVA) were then conducted from GLMs to determine whether the explanatory variables significantly influenced the occurrence probabilities of larval life events.

Finally, segmented linear models were used to describe the decreasing trends in larval condition over time for the different temperatures in seawater. Instead of fitting simple linear relationship, the segmented regression enables to adjust successive line segments on intervals of time, separated by breakpoints. In the present case, this approach is particularly relevant to quantify the abrupt changes in larval condition over time, the breakpoints reflecting critical threshold values below which the condition index drops due to starvation. Accordingly, segmented linear models were adjusted separately for each experimental condition to determine the temperature-specific breakpoint values.

Statistical analyses were performed in the R environment (R Core Team, 2018, version 3.5.1), using the packages "survival" (Therneau \& Lumley, 2014) and "PAmeasures" (Li \& Wang, 2019) for survival analyses and the package "segmented" for the segmented regressions (Muggeo, 2008).

\section{Results}

\subsection{Control conditions}

Free embryos of only five egg clutches were monitored in identical controlled conditions $\left(23.9 \pm 0.1^{\circ} \mathrm{C}\right.$ in freshwater) as one of them (\#4) was placed in seawater because of a dysfunction of the experimental system. All free embryos remained undeveloped (incomplete resorption of the yolk sac and mouth closed). Survival times of individuals placed in the control beakers differed significantly between the five egg clutches (log-rank test, $d f=4, \chi^{2}=139, p<0.001$; supplementary material, Fig. S1). These differences between clutches remained low as the survival expectancy (50\% survival from hatching) ranged from 107.0 to 125.0 hours (clutches $n^{\circ} 5$ and 2 , respectively), and the maximum survival time extended from 120.8 to 131.9 hours (clutches $n^{\circ} 6$ and 1 , respectively).

\subsection{Influence of temperature on larval development}

Whatever the temperature in freshwater, all free embryos died before the complete resorption of the yolk sac and oil globule, and their mouth remained closed. On the contrary, seawater water temperature significantly influenced the moment when yolk sac resorption, mouth opening, or oil globule resorption occurred (Table 2). Larval development was monitored in seawater for a total number of free embryos

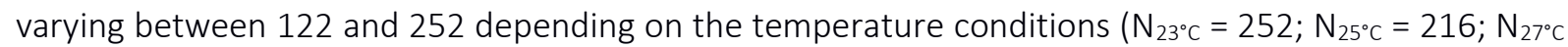
$\left.=122 ; \mathrm{N}_{29^{\circ} \mathrm{C}}=148 ; \mathrm{N}_{31^{\circ} \mathrm{C}}=141\right)$. The yolk sac resorption and the mouth opening occurred significantly earlier in high water temperatures (Fig. 2b, c), but the interaction between the time after hatching and temperature was non-significant (Table 2). Conversely, this interaction was significant for the oil globule resorption, which indicates a more gradual depletion of endogenous reserve at lower temperature 
whereas this depletion is more rapid at higher temperature (Fig. 2d). Overall, the yolk sac resorption occurred before the mouth opening. Finally, the oil globule was resorbed about 125 hours after hatching at $23{ }^{\circ} \mathrm{C}$ and only 77 hours after hatching at $31^{\circ} \mathrm{C}$ according to the logistic model.

In seawater, the five segmented regressions ( $\mathrm{R} 2$ ranging between 0.74 and 0.81 , all $p$-values $<0.001$ ) revealed that the larval condition index remained quite stable soon after hatching, or sometimes slightly increased, and then quickly dropped when threshold time values were reached (Fig.3). The breakpoints of segmented regressions differed between the temperature conditions, indicating that the first signs of starvation occurred earlier in warmer water. This critical threshold occurred 80 hours after hatching at $23^{\circ} \mathrm{C}$, whereas it occurred 52 hours after hatching at $30^{\circ} \mathrm{C}$.

\subsection{Influence of temperature on larval survival}

In freshwater, the survival regression model explained a large part of variability ( $R 2=0.93$ ) and revealed a significant effect of temperature on survival (Table 3). The among replicate variation was significant but its contribution to the total explained deviance remained poor. In freshwater, the duration of survival expectancy after hatching decreased as temperature increased from $>150$ hours at $21^{\circ} \mathrm{C}$ to $<50$ hours at $31{ }^{\circ} \mathrm{C}$ (Fig. 4a; supplementary material, Fig. S2). In seawater, larval survival decreased more progressively and larvae survived longer. The survival model explained a lower amount of variability (R2 $=0.24)$ than observed in freshwater, likely because data heterogeneity increased with time. The temperature significantly affected the survival and the effect of replicates remained low (Table 3). According to the Weibull model, 50\% of the larvae die within the first 175 hours after hatching at $23^{\circ} \mathrm{C}$ in seawater and within 100 hours after hatching at $31^{\circ} \mathrm{C}$ (Fig. 4b).

\section{Discussion}

Overall, this study demonstrated that water temperature is a key factor controlling larval mortality and the occurrence of critical larval life events such as mouth opening, yolk sac resorption, and oil globule resorption. Nevertheless, our results also pointed out some variation in survival between clutches of larvae kept in control freshwater conditions. Although our experiment was not designed to investigate potential genetic or maternal effects, the variability in larval survival related to clutch origins appeared lower than the differences observed between temperature conditions. For example, survival expectancy ranged between 107 and 125 hours in control freshwater condition $\left(23.9^{\circ} \mathrm{C}\right)$ when it was $>150$ hours at $21{ }^{\circ} \mathrm{C}$ and $<50$ hours at $31^{\circ} \mathrm{C}$. Nevertheless, future studies should consider developing crossed design experiments with dissimilar temperatures and larvae origins to determine how maternal (or genetic) effects can affect the sensitivity of amphidromous larvae to water warming. 
As observed in early life stages of most fish species, the larvae of amphidromous gobies are subjected to massive mortality during their marine phase. Survival rates of $S$. lagocephalus was estimated to be $1.10^{-5}$ or less at the end of the larval stage (Artzrouni, Teichert, \& Mara, 2014). The large number of eggs produced by amphidromous gobies contributes to offset the larval mortality induced by starvation, predation, or oceanic dispersion failures (Miller et al., 1988; McDowall, 2009). However, due to their small sizes, larvae survival strongly depends on environmental conditions such as food availability and temperature. The transition between fresh- and marine waters thus appears particularly sensitive for amphidromous gobies larvae as it coincides with the critical period during which larvae have to find and ingest food before the complete exhaustion of their endogenous reserves (Moriyama et al., 1998; Iguchi \& Mizuno, 1999). The food intake in Sicydiinae gobies is only possible after free embryos reach the sea and their mouth opens (e.g. Ellien et al., 2011; lida et al., 2010; Valade et al., 2009; this present study). In freshwater, the mouth of $S$. lagocephalus remains embryonic and free embryos die before the depletion of endogenous reserves (Valade et al., 2009; Ellien et al., 2011).

In freshwater, the free embryos survival sharply decreased with higher water temperature. This decrease in survival had been previously observed by Valade et al. (2009) but our results provide a better assessment of the relationship between temperature and survival, specifically documenting how survival rates sharply drop when time thresholds are reached. In this study, we observed that free embryos survival was four times longer at $21^{\circ} \mathrm{C}$ than at $31{ }^{\circ} \mathrm{C}$. This result suggests that free embryo survival rates vary greatly depending on the season and/or the location in the river from which they drift from. Indeed, besides the seasonal fluctuation in river temperature, the distance to the sea and altitude greatly influence the environmental conditions experienced by drifting free embryos (Lagarde et al., 2017). The downstream migration is longer when hatching occurs in upper reaches and free embryos are thus exposed to a wider range of temperatures, from the cold water of upstream reaches to the warmer ones downstream. Therefore, individuals hatching upstream have a greater probability of mortality than those hatching closer to the sea (Bell, 2009). They are also more sensitive to stream alterations (e.g. river obstacles, water reservoirs, flows regulation) that contribute to warm the water and increase the drifting duration (McRae, 2007; Lagarde et al., 2018; Jarvis \& Closs, 2019).

Once Sicydiinae free embryos reach brackish or marine waters, they initiate their physiological and morphological transformations (Valade et al., 2009; lida et al., 2010; Ellien, Werner, \& Keith, 2016). In our experiments, the timing of ontogenetic events were closely related to seawater temperature: yolk sac depletion always happening firstly, followed by the mouth opening and lastly the resorption of the oil globule (Fig. 5). Between the mouth opening and the first exogenous food intake, the energetic requirements appeared essentially fueled by the oil globule, as it has been commonly reported for other species (Gisbert, Conklin, \& Piedrahita, 2004; Sulaeman \& Fotedar, 2017). While the timing of yolk sac 
302

303

304

305

306

307

308

309

310

311

312

313

314

315

316

317

318

319

320

321

322

323

324

325

326

327

328

329

330

331

332

333

334

335

resorption and mouth opening were linearly related to the temperature, the effect of temperature on depletion of the oil globule was more rapid in warm waters. This observation agrees with unfed larvae surviving from 100 hours at $31{ }^{\circ} \mathrm{C}$ to 175 hours at $23^{\circ} \mathrm{C}$. These survival times in seawater also corroborate the results of lida et al. (2017) who observed that S. lagocephalus larvae survived five days (approx. $120 \mathrm{~h}$ ) when reared at temperatures ranging from 24 to $30^{\circ} \mathrm{C}$.

Whatever the temperature, the first signs of starvation appeared few hours after the mouth opening, suggesting that the temporal window for the first food intake is very narrow. Although feeding can potentially occur from the mouth opening to death of larvae (interval time ranging between 57 and 104 hours at $31^{\circ} \mathrm{C}$ and $23^{\circ} \mathrm{C}$, respectively), an extended period of starvation before first feeding can induce irreversible damages in anatomical and digestive structures of fish larvae (Ehrlich, Blaxter, \& Pemberton, 1976; Gisbert, Conklin, \& Piedrahita, 2004; Dou et al., 2005). Accordingly, we defined the critical period for first food intake as the interval of time between mouth opening (probability $=0.5$ ) and oil globule resorption (probability $=0.5$ ), i.e. the exhaustion of endogenous reserves (Fig. 5). The duration of this period appeared as short as about 30 hours between 28 and $31{ }^{\circ} \mathrm{C}$, whereas it extended to 54 hours at $23^{\circ} \mathrm{C}$. We assumed here that the opening of a functional mouth was associated with the transition to exogenous feeding when for some fish species exogenous feeding can be delayed by several hours after the mouth opens (Gisbert, Conklin, \& Piedrahita, 2004). If this is the case for amphidromous gobies, their critical period should be even shorter. For S. lagocephalus, further developments in larval rearing techniques, such as the observation of fed larvae, are still required to improve our understanding of their larval ecology (lida et al., 2017). More accurate observations will allow to assess with precision the point-of-no-return when larvae reach an irreversible state starvation, which probably occurs before the complete exhaustion of endogenous reserves (Ehrlich, Blaxter, \& Pemberton, 1976).

The results of our experiments confirmed the critical influence of water temperature on the development and survival of amphidromous goby larvae. During the summer peak of larval production (Lagarde et al., 2017), the critical period for first feeding is restricted to approximately 30 hours. Following Hort's (1914) reasoning, such narrow period for first feeding may increase the sensitivity of amphidromous gobies larvae to food limitations in the marine environment. Indeed, the seasonal fluctuation of plankton abundance and spatial distribution (e.g. patchiness) can lead to a mismatch between larvae and their plankton preys, finally affecting their survival (Cushing, 1990; Llopiz et al., 2014). In the Western Indian ocean, Roxy et al. (2016) reported that water warming was associated to a decrease of up to $20 \%$ in marine phytoplankton during the past six decades. The interacting effect of elevated temperature and limited food supply can thus induce harmful effects on growth and survival of fish larvae, when food availability cannot compensate the increased metabolic costs (McLeod et al., 2013). Although many Sicydiinae gobies, such as S. lagocephalus, are obligate amphidromous, other 
species can exhibit facultative migratory behaviors (Hogan et al. 2014). For these species, global changes will affect the fitness of migrants as the passages from rivers to ocean and back become more precarious. This could induce a shift in the proportions of life history traits towards more freshwater individuals. Further studies are thus needed to assess the impact of climate change on migratory behaviors of amphidromous species and its implication for the success of migratory strategies.

\section{Acknowledgements}

We thank Brendan Ebner and the two anonymous referees for their comments and suggestions that have contributed to improve the relevance of our manuscript. We are grateful to Henri Grondin who helped us to collect the eggs in the river. The study was supported by the European Regional Development Fund and the European Social Fund, Région Réunion (Avenue René Cassin, BP 7190, 97719 Saint Denis, Cedex 9). This scientific study was approved by the local environmental authorities in accordance with the certificate no. 13- 030/DEAL/SEB/UPEMA delivered by the Direction de l’Environnement, de l'Aménagement et du Logement de La Réunion (Saint- Denis, La Réunion).

\section{Data Availability Statement}

The data that support the findings of this study are available on request from the corresponding author.

\section{References}

Artzrouni, M., Teichert, N., \& Mara, T. 2014. A Leslie matrix model for Sicyopterus lagocephalus in La Réunion: Sensitivity, uncertainty and research prioritization. Mathematical Biosciences, 256: 1827.

Balon, E. K. 1975. Terminology of intervals in fish development. Journal of the Fisheries Board of Canada, 32: 1663-1670.

Bardonnet, A., Gaudin, P., Grolet, O., \& Thorpe, J. E. 1993. Presence of an oesophageal mucus plug at the time of emergence in grayling (Thymallus thymallus) and Atlantic salmon (Salmo salar). Journal of fish biology, 43: 500-502.

Bell, K. N. I. 1994. Life cycle, early life history, fisheries and recruitment dynamics of diadromous gobies of Dominica, WI, emphasising Sicydium punctatum Perugia. Memorial University of Newfoundland, Biology Dept., St. John's, NL, CA.

Bell, K. N. I. 2009. What comes down must go up: the migration cycle of juvenile-return anadromous taxa. In: American Fisheries Society Symposium, 69: 321-341.

Bell, K. N. I., \& Brown, J. A. 1995. Active salinity choice and enhanced swimming endurance in 0 to 8-d- 
old larvae of diadromous gobies, including Sicydium punctatum (Pisces), in Dominica, West Indies. Marine Biology, 121: 409-417.

Brasher, A. M. D. 2003. Impacts of human disturbances on biotic communities in Hawaiian streams. BioScience, 53: 1052-1060.

China, V., \& Holzman, R. 2014. Hydrodynamic starvation in first-feeding larval fishes. Proceedings of the National Academy of Sciences of the United States of America, 111: 8083-8088.

Conand, F., Marsac, F., Tessier, E., \& Conand, C. 2008. A ten-year period of daily sea surface temperature at a coastal station in Reunion Island, Indian Ocean (July 1993-April 2004): patterns of variability and biological responses. Western Indian Ocean Journal of Marine Science, 6: 1-16.

Cushing, D. H. 1990. Plankton production and year-class strength in fish populations: An update of the match/mismatch hypothesis. Advances in Marine Biology, 26: 249-293.

Delacroix, P., \& Champeau, A. 1992. Ponte en eau douce de Sicyopterus lagocephalus (Pallas) poisson Gobiidae amphibionte des rivières de la Réunion. Hydroécologie Appliquée, 4: 49-63.

Dou, S. Z., Masuda, R., Tanaka, M., \& Tsukamoto, K. 2005. Effects of temperature and delayed initial feeding on the survival and growth of Japanese flounder larvae. Journal of Fish Biology, 66: 362377.

Ehrlich, K. F., Blaxter, J. H. S., \& Pemberton, R. 1976. Morphological and histological changes during the growth and starvation of herring and plaice larvae. Marine Biology, 35: 105-118.

Ellien, C., Causse, R., Werner, U., Teichert, N., \& Rousseau, K. 2020. Looking for environmental and endocrine factors inducing the transformation of Sicyopterus lagocephalus (Pallas 1770) (Teleostei: Gobiidae: Sicydiinae) freshwater prolarvae into marine larvae. Aquatic Ecology, 54: 163-180.

Ellien, C., Valade, P., Bosmans, J., Taillebois, L., Teichert, N., \& Keith, P. 2011. Influence of salinity on larval development of Sicyopterus lagocephalus (Pallas, 1770) (Gobioidei). Cybium, 35: 381-390.

Ellien, C., Werner, U., \& Keith, P. 2016. Morphological changes during the transition from freshwater to sea water in an amphidromous goby, Sicyopterus lagocephalus (Pallas 1770)(Teleostei). Ecology of freshwater fish, 25: 48-59.

Fyhn, H. J. 1989. First feeding of marine fish larvae: are free amino acids the source of energy? Aquaculture, 80: 111-120.

Gisbert, E., Conklin, D. B., \& Piedrahita, R. H. 2004. Effects of delayed first feeding on the nutritional 
condition and mortality of California halibut larvae. Journal of Fish Biology, 64: 116-132.

397

398

399

400

401

402

403

404

405

406

407

408

409

410

411

412

413

414

415

416

417

418

419

420

421

422

423

424

Ha, P. Y., \& Kinzie, R. A. 1996. Reproductive biology of Awaous guamensis, an amphidromous Hawaiian goby. Environmental Biology of Fishes, 45: 383-396.

Hjort, J. 1914. Fluctuations in the great fisheries of northern Europe viewed in the light of biological research. ICES, 1914.

Houde, E. D., \& Schekter, R. C. 1980. Feeding by marine fish larvae: developmental and functional responses. Environmental Biology of Fishes, 5: 315-334.

Hogan, J.D., Blum, M.J., Gilliam, J.F., Bickford, N. \& McIntyre, P.B. (2014). Consequences of alternative dispersal strategies in a putatively amphidromous fish. Ecology 95, 2397-2408

Iguchi, K., \& Mizuno, N. 1999. Early starvation limits survival in amphidromous fishes. Journal of Fish Biology, 54: 705-712.

lida, M., Kondo, M., Tabouret, H., Maeda, K., Pecheyran, C., Hagiwara, A., Keith, P., \& Tachihara, K. 2017. Specific gravity and migratory patterns of amphidromous gobioid fish from Okinawa Island, Japan. Journal of Experimental Marine Biology and Ecology, 486: 160-169.

lida, M., Watanabe, S., \& Tsukamoto, K. 2013. Riverine life history of the amphidromous goby Sicyopterus japonicus (Gobiidae: Sicydiinae) in the Ota River, Wakayama, Japan. Environmental Biology of Fishes, 96: 645-660.

lida, M., Watanabe, S., Yamada, Y., Lord, C., Keith, P., \& Tsukamoto, K. 2010. Survival and behavioral characteristics of amphidromous goby larvae of Sicyopterus japonicus (Tanaka, 1909) during their downstream migration. Journal of Experimental Marine Biology and Ecology, 383: 17-22.

Jarvis, M. G., \& Closs, G. P. 2015. Larval drift of amphidromous Gobiomorphus spp. in a New Zealand coastal stream: a critical spatial and temporal window for protection. New Zealand Journal of Marine and Freshwater Research, 49: 439-447.

Jarvis, M. G., \& Closs, G. P. 2019. Water infrastructure and the migrations of amphidromous species: impacts and research requirements. Journal of Ecohydraulics, 4: 4-13.

Kamler, E. 2012. Early life history of fish: an energetics approach (Vol. 4). Springer Science \& Business Media.

Keith, P. 2003. Biology and ecology of amphidromous Gobiidae of the Indo-Pacific and the Caribbean regions. Journal of fish biology, 63: 831-847. 
Lagarde, R., Teichert, N., Faivre, L., Grondin, H., Magalon, H., Pirog, A., Valade, P., \& Ponton, D. 2018. Artificial daily fluctuations of river discharge affect the larval drift and survival of a tropical amphidromous goby. Ecology of Freshwater Fish, 27(3): 646-659.

Lagarde, R., Teichert, N., Grondin, H., Magalon, H., Pirog, A., \& Ponton, D. 2017. Temporal variability of larval drift of tropical amphidromous gobies along a watershed in Réunion Island. Canadian Journal of Fisheries and Aquatic Sciences, 74: 948-957.

Lagarde, R., Teichert, N., Valade, P., \& Ponton, D. 2020. Structure of small tropical island freshwater fish and crustacean communities: A niche-or dispersal-based process? Biotropica, 1-12.

Li, G., \& Wang, X. 2019. Prediction accuracy measures for a nonlinear model and for right-censored time-to-event data. Journal of the American Statistical Association, 114(528): 1815-1825.

Llopiz, J. K., Cowen, R. K., Hauff, M. J., Ji, R., Munday, P. L., Muhling, B. A., Peck, M. A., Richardson, D. E., Sogard, S., \& Sponaugle, S. 2014. Early life history and fisheries oceanography new questions in a changing world. Oceanography, 27: 26-41.

Lord, C., Lorion, J., Dettai, A., Watanabe, S., Tsukamoto, K., Cruaud, C., \& Keith, P. 2012. From endemism to widespread distribution: phylogeography of three amphidromous Sicyopterus species (Teleostei: Gobioidei: Sicydiinae). Marine Ecology Progress Series, 455: 269-285.

Manacop, P. R. 1953. The life history and habits of the goby, Sicyopterus extraneus Herre (anga) Gobiidae with an account of the goby-fry fishery of Cagayan River, Oriental Masamis. Philipp J Fish, 2: $1-57$.

McCasker, N., Humphries, P., Meredith, S., \& Klomp, N. 2014. Contrasting patterns of larval mortality in two sympatric riverine fish species: A test of the critical period hypothesis. PLOS ONE, 9(10): e109317.

McDowall, R. M. 2009. Early hatch: a strategy for safe downstream larval transport in amphidromous gobies. Reviews in Fish Biology and Fisheries, 19: 1.

McLeod, I. M., Rummer, J. L., Clark, T. D., Jones, G. P., McCormick, M. I., Wenger, A. S., \& Munday, P. L. 2013. Climate change and the performance of larval coral reef fishes: the interaction between temperature and food availability. Conservation Physiology, 1.1.

McRae, M. G. 2007. The potential for source-sink population dynamics in Hawaii's amphidromous fishes. Biology of Hawaiian Streams and Estuaries. Bishop Mus. Bull. Cult. Environ. Stud, 3: 87-98.

Miller, T. J., Crowder, L. B., Rice, J. A., \& Marschall, E. A. 1988. Larval size and recruitment mechanisms 
in fishes: toward a conceptual framework. Canadian Journal of Fisheries and Aquatic Sciences, 45: $1657-1670$.

Moriyama, A., Yanagisawa, Y., Mizuno, N., \& Omori, K. 1998. Starvation of drifting goby larvae due to retention of free embryos in upstream reaches. Environmental Biology of Fishes, 52: 321-329.

Muggeo, V. M. R. 2008. Segmented: an R package to fit regression models with broken-line relationships. R news, 8: 20-25.

R Core Team. 2018. R: A language and environment for statistical computing. R Foundation for Statistical Computing, Vienna, Austria. URL https://www.R-project.org/.

Roxy, M. K., Modi, A., Murtugudde, R., Valsala, V., Panickal, S., Prasanna Kumar, S., Ravichandran, M., Vichi, M., \& Lévy, M. 2016. A reduction in marine primary productivity driven by rapid warming over the tropical Indian Ocean. Geophysical Research Letters, 43: 826-833.

Roxy, M. K., Ritika, K., Terray, P., \& Masson, S. 2014. The curious case of Indian Ocean warming. Journal of Climate, 27: 8501-8509.

Sulaeman, \& Fotedar, R. 2017. Yolk utilization and growth during the early larval life of the Silver Perch, Bidyanus bidyanus (Mitchell, 1838). International Aquatic Research, 9: 107-116.

Teichert, N., Keith, P., Valade, P., Richarson, M., Metzger, M., \& Gaudin, P. 2013. Breeding pattern and nest guarding in Sicyopterus lagocephalus, a widespread amphidromous Gobiidae. Journal of Ethology, 31: 239-247.

Teichert, N., Valade, P., Fostier, A., Grondin, H., \& Gaudin, P. 2016. Reproductive biology of an endemic amphidromous goby, Cotylopus acutipinnis, from la Réunion Island. Marine and Freshwater Research, 67: 526-536.

Teichert, N., Valade, P., Fostier, A., Lagarde, R., \& Gaudin, P. 2014. Reproductive biology of an amphidromous goby, Sicyopterus lagocephalus, in La Réunion Island. Hydrobiologia, 726: 123141.

Teichert, N., Valade, P., Grondin, H., Trichet, E., Sardenne, F., \& Gaudin, P. 2016. Pelagic larval traits of the amphidromous goby Sicyopterus lagocephalus display seasonal variations related to temperature in La Réunion Island. Ecology of Freshwater Fish, 25: 234-247.

Therneau, T. M., \& Lumley, T. 2014. Package 'survival.' Survival analysis Published on CRAN, 2: 3.

Valade, P., Lord, C., Grondin, H., Bosc, P., Taillebois, L., lida, M., Tsukamoto, K., \& Keith, P. 2009. Early life history and description of larval stages of an amphidromous goby, Sicyopterus lagocephalus 
486

487

488

489

490

491

492

493

494

495

496

497

498

499

Walter, R. P., Hogan, J. D., Blum, M. J., Gagne, R. B., Hain, E. F., Gilliam, J. F., \& McIntyre, P. B. 2012. Climate change and conservation of endemic amphidromous fishes in Hawaiian streams. Endangered Species Research, 16: 261-272.

Watson, S., Allan, B. J. M., McQueen, D. E., Nicol, S., Parsons, D. M., Pether, S. M. J., Pope, S., Setiawan, A. N., Smith, N., \& Wilson, C. 2018. Ocean warming has a greater effect than acidification on the early life history development and swimming performance of a large circumglobal pelagic fish. Global change biology, 24: 4368-4385.

Woodward, G., Perkins, D. M., \& Brown, L. E. 2010. Climate change and freshwater ecosystems: impacts across multiple levels of organization. Philosophical Transactions of the Royal Society B: Biological Sciences, 365: 2093-2106.

Yoseda, K., Dan, S., Sugaya, T., Yokogi, K., Tanaka, M., \& Tawada, S. 2006. Effects of temperature and delayed initial feeding on the growth of Malabar grouper (Epinephelus malabaricus) larvae. Aquaculture, 256: 192-200. 
500 Table 1: Experimental conditions experienced by Sicyopterus lagocephalus free embryos and larvae.

501 Egg clutch refer to the origin of the individuals placed in the different conditions. Temperature initially

502 planned and mean and standard deviation of recorded values during the experiments are indicated.

\begin{tabular}{ccccccc}
\hline $\begin{array}{c}\text { Experimental } \\
\text { conditions }\end{array}$ & Egg clutch & $\begin{array}{c}\text { Number of } \\
\text { replicates }\end{array}$ & $\begin{array}{c}\text { Number of free } \\
\text { embryos }\end{array}$ & $\begin{array}{c}\text { Planned } \\
\text { temperature }\left({ }^{\circ} \mathrm{C}\right)\end{array}$ & $\begin{array}{c}\text { Recorded temperature }\left({ }^{\circ} \mathrm{C}\right) \\
\text { mean }\end{array}$ & sd \\
\hline \multirow{5}{*}{ Freshwater } & 1 & 3 & 120 & 21 & 21.16 & 0.08 \\
& 1 & 3 & 120 & 23 & 23.14 & 0.15 \\
& 2 & 3 & 120 & 25 & 24.88 & 0.13 \\
& 3 & 3 & 120 & 27 & 26.20 & 0.06 \\
& 3 & 3 & 120 & 29 & 28.16 & 0.07 \\
\hline \multirow{5}{*}{ Seawater } & 2 & 3 & 120 & 31 & 30.98 & 0.09 \\
& 4 & 3 & 120 & 23 & 23.20 & 0.06 \\
& 5 & 3 & 120 & 25 & 24.88 & 0.05 \\
& 6 & 3 & 120 & 27 & 26.73 & 0.09 \\
& 6 & 3 & 120 & 29 & 29.54 & 0.07 \\
\hline
\end{tabular}

503

504

505

506 
507 Table 2: Deviance analyses conducted on the generalized logistic regressions adjusted for modelling 508 the occurrence of a) yolk sac resorption, b) mouth opening, and c) oil globule resorption in response 509 to time after hatching (Time) and seawater temperature (T).

\begin{tabular}{lcccc}
\hline Model & $\begin{array}{c}\text { Residual } \\
\text { deviance }\end{array}$ & Residual d.f. & $\begin{array}{c}\text { Explained } \\
\text { deviance }\end{array}$ & $p$-value \\
\hline a) Yolk sac resorption & 1006.3 & 878 & - & \\
Null & 130.9 & 877 & 875.4 & $<0.001$ \\
Time & 106.1 & 876 & 24.8 & $<0.001$ \\
$\log (\mathrm{T})$ & 106.1 & 875 & 0 & 0.853 \\
Time $x \log (\mathrm{T})$ & & & & \\
\hline b) Mouth opening & 1142.3 & 878 & - & \\
Null & 187.3 & 877 & 955 & $<0.001$ \\
Time & 73 & 876 & 114.3 & $<0.001$ \\
$\log (\mathrm{T})$ & 72 & 875 & 1 & 0.321 \\
Time $x \log (\mathrm{T})$ & & & & \\
\hline c) Oil globule resorption & 1200.1 & 878 & - & $<0.001$ \\
Null & 317.1 & 877 & 883 & $<0.001$ \\
Time & 188.5 & 876 & 128.7 & $<0.001$ \\
\hline $\log (\mathrm{T})$ & 160.9 & 875 & 27.6 & \\
Time $x \log (\mathrm{T})$ & & & &
\end{tabular}

510

511

512 
514 Table 3: Outputs of the deviance analyses conducted on the survival regression models for assessing 515 the significance of temperature and experimental replicates on survival in a) freshwater and in b) 516 seawater.

\begin{tabular}{ccccc}
\hline \multicolumn{1}{c}{ Model } & $\begin{array}{l}\text { Residual } \\
\text { deviance }\end{array}$ & Residual d.f. & $\begin{array}{c}\text { Explained } \\
\text { deviance }\end{array}$ & p-value \\
\hline a) Survival in freshwater & & & & \\
Null & 7078.8 & 718.0 & - & \\
log(T) & 5234.0 & 717.0 & 1844.7 & $<0.001$ \\
Replicates & 5122.8 & 712.8 & 111.2 & $<0.001$ \\
\hline b) Survival in seawater & & & & \\
Null & 6024.6 & 598.0 & - & \\
log(T) & 5897.1 & 597.0 & 127.5 & $<0.001$ \\
Replicates & 5845.5 & 592.8 & 51.6 & $<0.001$ \\
\hline
\end{tabular}

517 


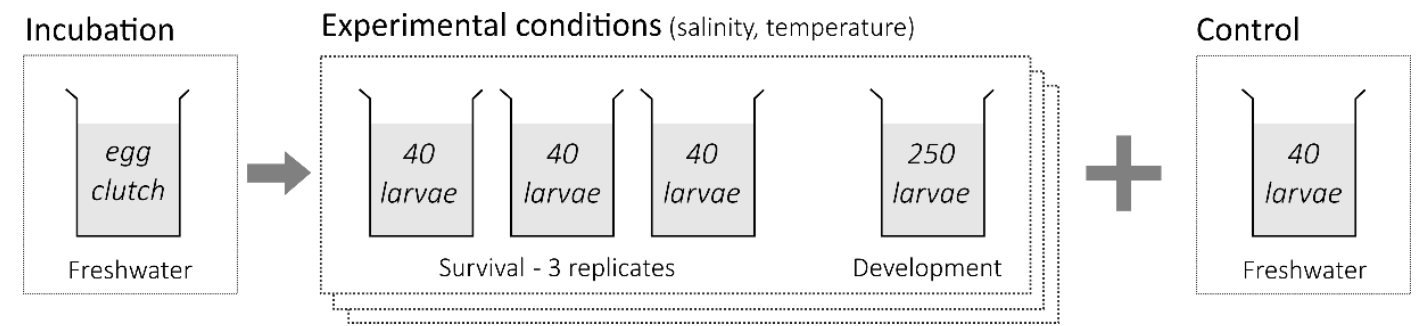

521 Figure 1: Experimental design used for assessing the impact of water temperature on the free embryos

522 and larvae of Sicyopterus lagocephalus in freshwater and seawater. Survival was monitored in three

523 replicates placed in experimental conditions while the fourth was used to follow larvae development. A

524 fifth beaker was maintained in controlled freshwater conditions to monitor survival in identical 525 temperature for each clutch. 


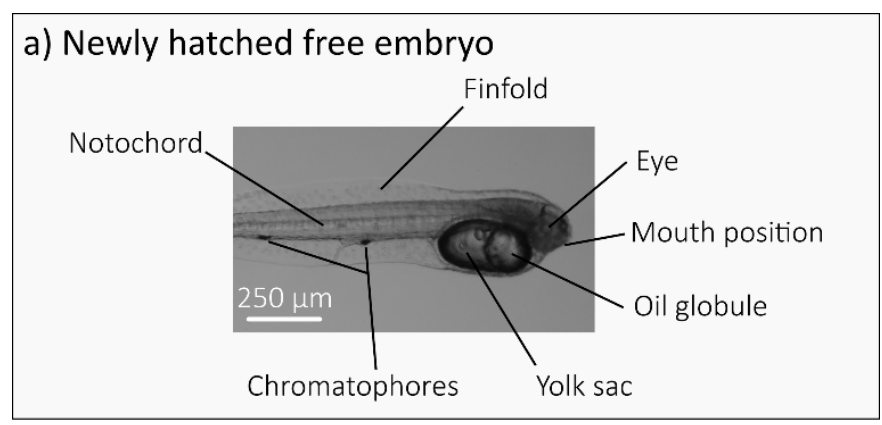

b) Yolk sac resorption

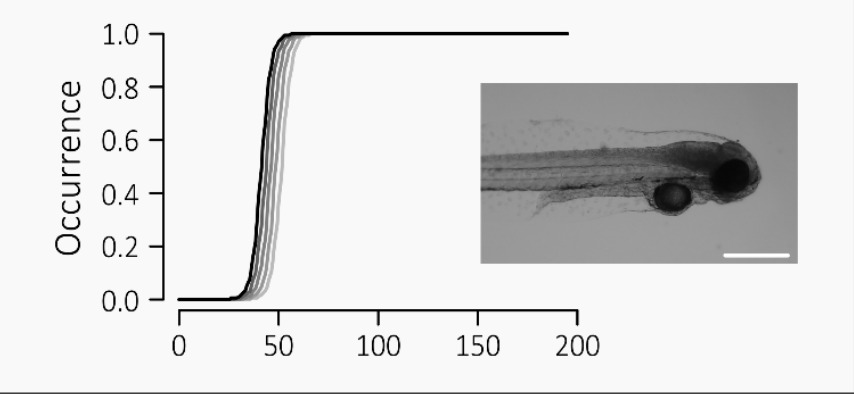

c) Mouth opening

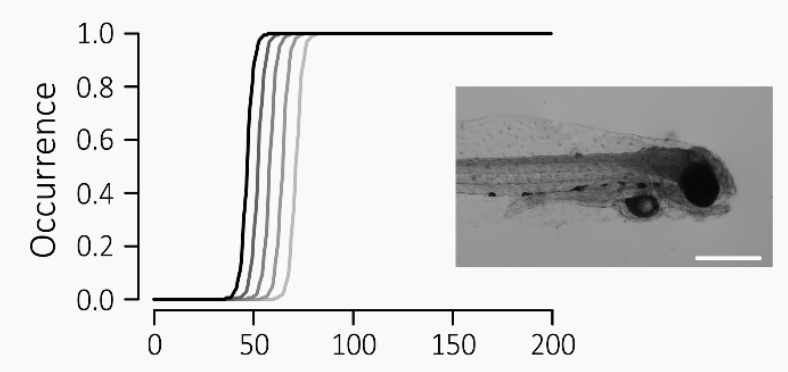

d) Oil globule resorption

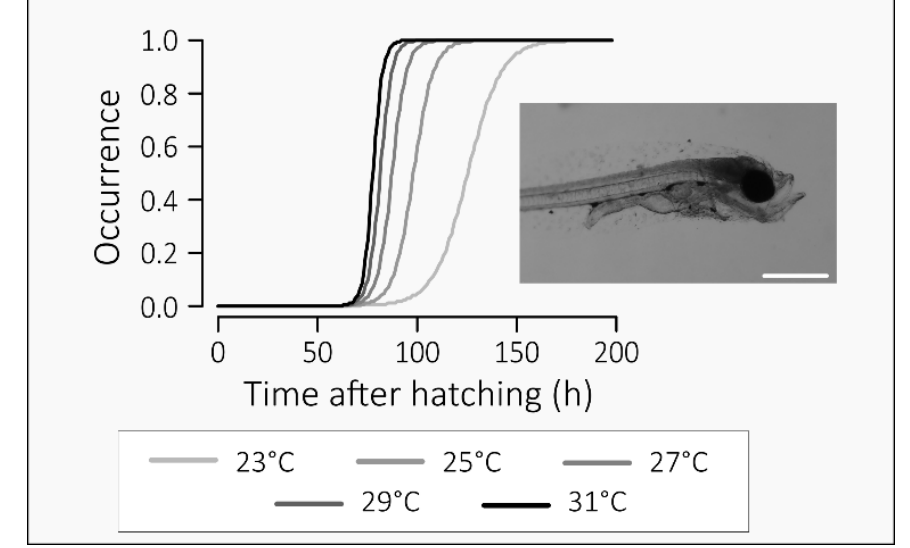

528 Figure 2: Morphological changes and developmental events in Sicyopterus lagocephalus. a) Newly 529 hatched free embryo and morphological attributes in freshwater. Occurrence probabilities predicted 530 from logistic models for b) yolk sac resorption, c) mouth opening, and d) oil globule resorption according 531 to the temperature in seawater. White scale bar: $250 \mu \mathrm{m}$. 


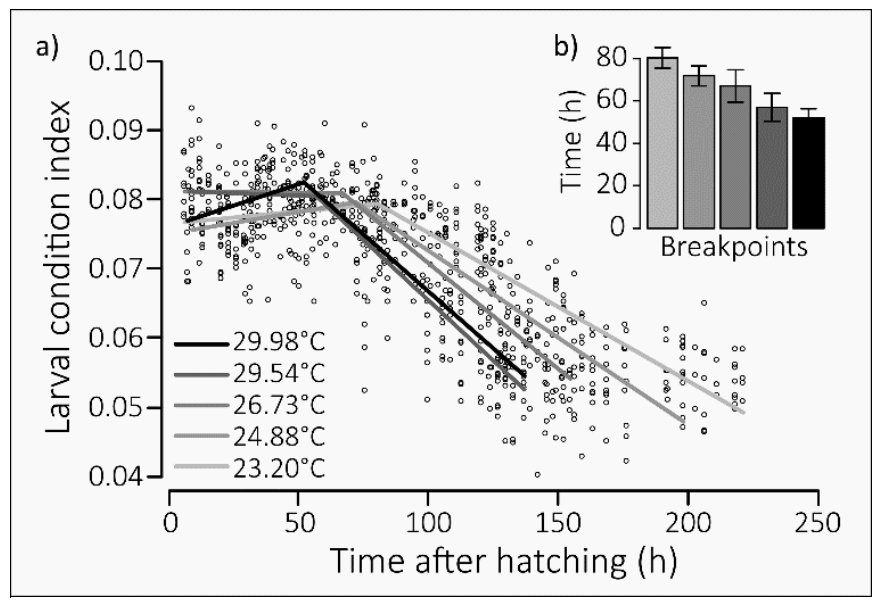

533 Figure 3: Influence of temperature on the larval condition index of Sicyopterus lagocephalus in seawater.

534 (a) The segmented lines are presented with (b) details on the breakpoints derived from the segmented 535 regression models. The bars represent standard deviation of the breakpoint estimates. 

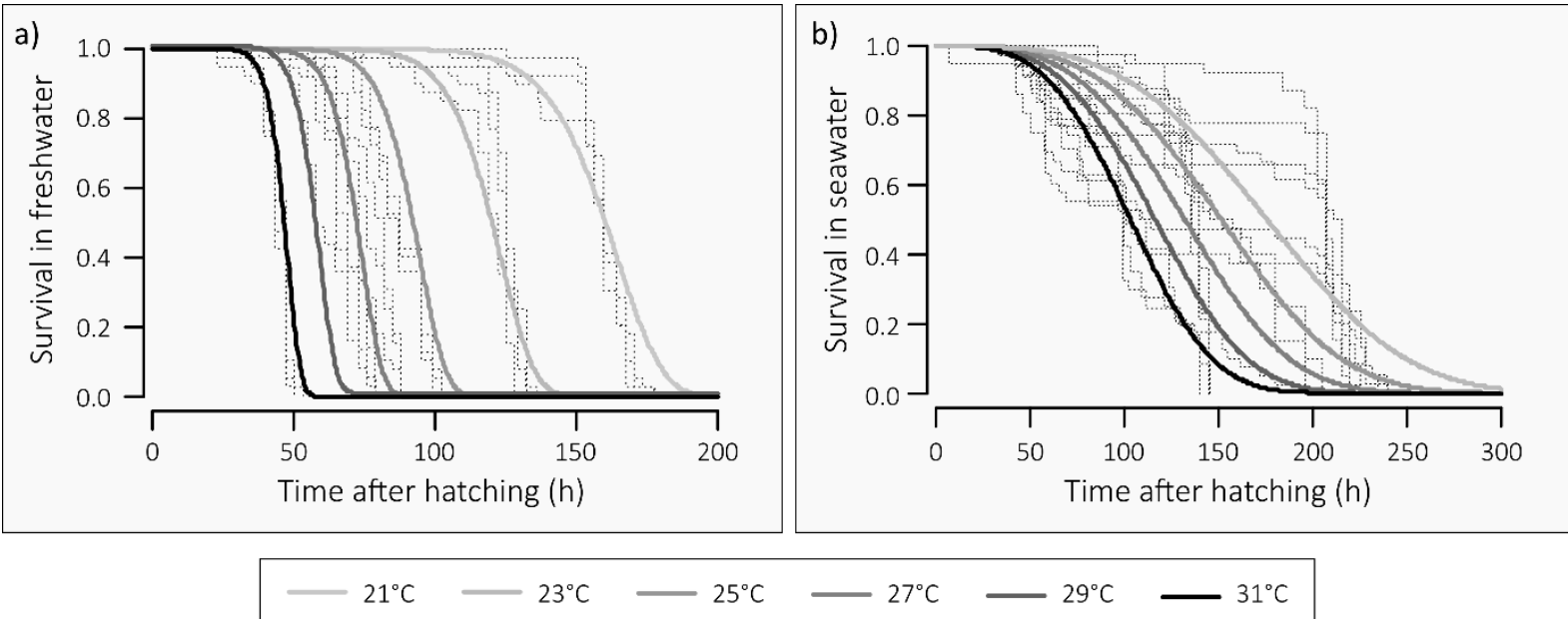

$27^{\circ} \mathrm{C}$

$29^{\circ} \mathrm{C}$

537 Figure 4: Survival probabilities of Sicyopterus lagocephalus free embryos and larvae in a) freshwater and

538 b) seawater depending on water temperatures, as predicted by the Weibull survival regression models

539 (continuous lines). The dotted lines reflect the actual observations of the free embryos and larvae

540 survival recorded among the different experimental conditions and replicates. 


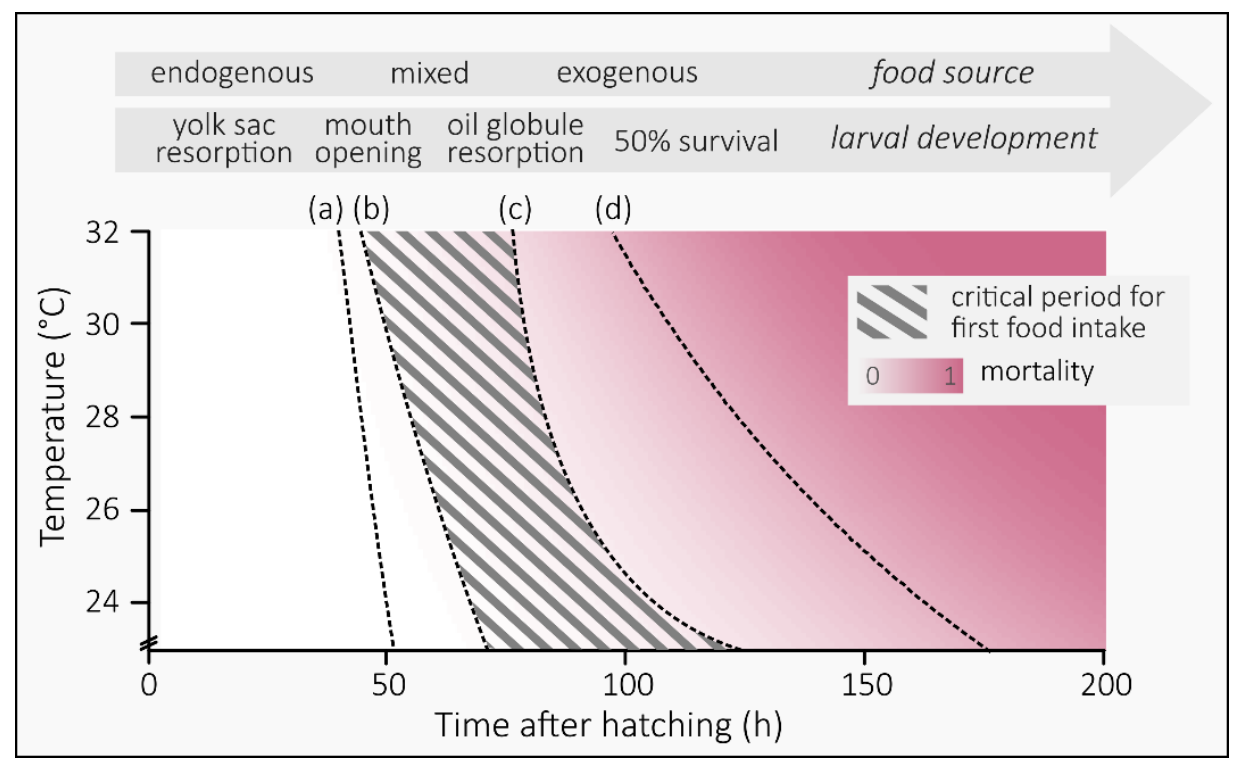

542 Figure 5: Synthetic overview of the influence of seawater temperature on larval survival and early life

543 events in Sicyopterus lagocephalus. Isoprobability curves $(\mathrm{p}=0.5)$ of occurrence of a) yolk sac resorption,

544 b) mouth opening, c) oil globule resorption, and d) 50\% survival are provided in response to the

545 temperature experienced in seawater. The critical period for first food intake was defined as the interval

546 time between the mouth opening and the resorption of oil globule, which denotes the complete 547 depletion of endogenous reserves. 